\title{
A latent class analysis on adolescents media use and associations with health related quality of life.
}

\author{
Milena Foerster ${ }^{1,2}$, Martin Röösli ${ }^{1,2}$ \\ ${ }^{1}$ Swiss Tropical and Public Health Institute, Department of Epidemiology and Public Health, Basel, \\ Switzerland \\ ${ }^{2}$ University of Basel, Basel, Switzerland
}

\section{Corresponding author}

Prof. Dr. Martin Röösli

Swiss Tropical and Public Health Institute

Socinstrasse 57

P.O. Box

CH-4002 Basel

E-Mail martin.roosli@unibas.ch

Tel. $\quad+41(0) 612848383$

Fax +41(0)612848501

\section{Financial Disclosure}

The authors have no financial relationships relevant to this article to disclose. 


\begin{abstract}
Purpose: Recent studies linked adolescents' media use to a variety of physical, psychological and social impairments. However, research neglected that adolescents' media use is complex and includes various combinations of activities such as mobile internet browsing, calling, online gaming or use of social network sites.
\end{abstract}

Methods: The aim of this study is to use latent class analysis in a sample 895 Swiss adolescents to classify different media usage types based on eleven media use variables. Subsequently, associations of these classes with health related quality of life (HRQoL) as measured by the KIDSCREEN-52 questionnaire were assessed using multivariable regression models adjusted for relevant confounding factors.

Results: Five distinct media use classes could be identified: Low Use, Medium Use, Gaming, Call Preference and High Social Use. The Low Use class reported highest and the High Social Use class lowest HRQoL on the KIDSCREEN scales Moods and Emotions (mean adjusted scores: 55.1 (95\%CI: 53.8; 57.0) vs. 49.1 (47.5; 50.7)), Self-Perception (51.8 (50.3; 53.3) vs. 48.0 (46.7; 49.28), Parents and Home Life (53.3 (51.7; 54.9) vs. $48.6(47.2 ; 50.0))$ and School Environment $(52.7(51.3 ; 54.0)$ vs. 49.3 $(48.2 ; 50.7))$. On the subscale Social Support and Peers the pattern was reversed. The Low Use class indicated least and the High Social Use class most well-being $(48.5(47.0 ; 50.0)$ vs. $53.8(52.4 ; 55.3))$. Conclusions: Latent class analyses is a fruitful approach to differentiate between various media usage types and is expected to better characterize and evaluate potential causal associations between media use and HRQoL.

Keywords: Media use, Smartphone, Social media, Adolescents, Latent class analysis, HRQoL 


\section{Introduction}

According to the International Telecommunication Union (ITU) in 2015 the penetration rate of mobile phone subscriptions in developed countries worldwide exceeded 120\%. In Switzerland the rate was even higher with 140 mobile phone subscriptions per 100 inhabitants. Coincidentally with the vast increase in prevalence, the age of owning the first mobile phone is decreasing. In a recent representative survey of 6-13 year old children in Switzerland 52\% stated to own a mobile phone. In a related study investigating over 1000 12-19 year old adolescents the penetration rate was 99\% (Suter et al., 2015; Waller et al., 2016). Of those devices 97\% were smartphones, which allow the user to access the internet from everywhere and additionally ease mobile communication through the use of various applications (“Apps”) such as Facetime or WhatsApp. But frequent use of media devices is not restricted to Smartphones. In the same survey over $76 \%$ of the adolescents stated to possess an own PC or laptop, about $53 \%$ of the adolescents also used an MP3 player, $45 \%$ owned a portable game console and $44 \%$ a digital camera.

Although one could assume that "digital natives" who grow up surrounded by new media technologies should have adopted to this rapid technological change more easily than "digital immigrants" (Prensky, 2001), adverse health effects have been associated with the use of new media in young people.

A growing body of research focuses on frequent media use defined as problematic behavior which causes harm to the individual. Several questionnaires have been developed to assess addictive use of online gaming, the internet, social network sites or Smartphones (Andreassen et al., 2012; Foerster et al., 2015; Wölfling et al., 2011; Young, 1998). One of these constructs, Internet Gaming Disorder (IGD) has even gained sufficient attention by clinicians to be included in the appendix of the DSM-5 manual for mental disorders as a research category. Like other behavioral addictions IGD is defined as maintaining a behavior despite its negative social and individual consequences. Excessive online gaming has been linked to impulsive, aggressive and ADHD-like behavior, depressive tendencies, sleep problems or anxiety (Ding et al., 2014; Lam, 2014; Mehroof et al., 2010; Stetina et al., 2011). Interestingly, similar symptoms have been linked to problematic mobile phone use (Billieux et al., 
2008; Demirci et al., 2015; Lee et al., 2015; Lemola et al., 2014; Roser et al., 2015; Roser et al., 2016), Internet (Chih-Hung Ko et al., 2014; C-H Ko et al., 2012; Ostovar et al., 2016; Young et al., 1998) and social network use (Banyai et al., 2017; Feinstein et al., 2013; Hong et al., 2014; Schou Andreassen et al., 2016; Tandoc et al., 2015). However, due to the qualitatively different contents media technologies may be used for (e.g. texting, calling, social network platforms, surfing, gaming...) there might be reasonable doubt that they all relate to the same health impairments. And indeed, it is heavily discussed if addictions to different kind of media should be regarded as one or separated concepts (Billieux, Maurage, et al., 2015; Choi et al., 2015; Király et al., 2014; Pontes et al., 2014).

Differences amongst types of media use are emphasized by studies focusing on the social implications of media use types. (Online) social communication facilitated through mobile phones and social media was found to be related to the need to belong, higher levels of loneliness (Abeele et al., 2013; Bian et al., 2015), female gender (Bianchi et al., 2005) and has been accompanied by social stress and low self-regulation (van Deursen et al., 2015). Still, benefits of social network use have also been highlighted. In a longitudinal study of Steinfield and colleagues Facebook use increased social capital and well-being through building and maintaining social relationships. This effect was even more pronounced for persons with initial low self-esteem and less life-satisfaction (Steinfield et al., 2008). In contrast, online gaming is more prevalent in male and was found to go along with hostile cognitions, to decrease the quality of interpersonal relationships and heighten social anxiety (Choo et al., 2010; Kuss et al., 2012; Lo et al., 2005).

Similarly, studies on media users' personality propose differences between media types. In a German study comparing a sample of 115 individuals diagnosed with Internet Gaming Disorder to nonaddicted controls pathological online gamers showed higher neuroticism, decreased conscientiousness and low extraversion applying the NEO FFI questionnaire based on the BIG-5 personality dimensions (Müller et al., 2013). Differently, high extraversion, narcissism and openness to experiences was found in high social network (Correa et al., 2010; Ong et al., 2011; Wang et al., 2015) and 
extraversion, low self-esteem and trait social anxiety in high mobile phone users (Bianchi et al., 2005; Ehrenberg et al., 2008).

Despite these various attempts to understand the impact of media use on well-being by linking it to personality and social factors the picture remains blurred. The main problems might lie in the usually limited focus on single types of media use or applications and the restriction to their problematic uses. This design does not account for the nowadays habitual combined use of many media devices and applications in parallel and might over-pathologize sociological changes. Thus, in particular adolescents' complex media use - including not only a number of different devices but also the way they handle them - remains poorly understood. In our opinion this limited view is likely to produce confounded results through the high intercorrelation amongst the variables and might lead to exposure misclassification.

Studies looking at media use as interplay of different usage domains are rare. Two recent studies focusing on the relation between problematic internet and problematic smartphone use introduced latent class analysis as an effective method for identifying different media usage groups among Asian adolescents and college students respectively (Kim et al., 2016; Mok et al., 2014). Mok et al identified in each of two gender-separated analysis three classes (high, medium and low) of internet and smartphone addiction levels simultaneously whereas Kim et al found three additional user groups by cross-secting amount of smartphone and internet use (e.g. low smartphone but high internet use). As a shortcoming, both studies were restricted to the problematic use of only two variables to identify the classes neither taking into account different types and motives of habitual media use nor the implicit differences amongst both media, e.g. the higher accessibility to online social communication via the portable smartphone.

Hypothesizing individual media use being a more complex composition of use variables (such as preferences for messaging, calling, gaming, surfing or using social network sites) we conducted a latent class analysis in an adolescent sample from Switzerland aiming at identifying more distinct user profiles. Since knowledge regarding general media use in adolescents is scarce the study is of exploratory nature and no predictions were made concerning the latent structure. Furthermore we 
assessed the relationship of the obtained profiles with health related quality of life for a better understanding of media use in adolescents' life.

\section{Methods}

\subsection{Study population}

The HERMES cohort (Health Effects Related to Mobile phone usE in adolescentS) consists of adolescents attending $7^{\text {th }}$ to $9^{\text {th }}$ grade in Switzerland. Here we report about the baseline investigations, which were conducted in two waves in 2012/2013 and 2014/2015 in Central Switzerland and Basel. Participating adolescents were recruited through initial phone contact with the head of the school and a subsequent informational visit in the respective classes. Participation was voluntary and had to be preceded by informed consent of the adolescents and a parent. The investigation took place in school during school time. During the investigation students filled out a paper and pencil questionnaire.

Ethical approval for the conduct of the study was received from the ethical committee of Lucerne, Switzerland on May 9, 2012.

\subsection{Material}

\subsubsection{Mobile phone and general media use}

Student's media use was assessed through questionnaire and included detailed questions about their quantitative use of mobile phones and other media devices, as well as questions on different use possibilities like social media use or online gaming. The questions entering the latent class analysis were mostly rated via 4-6 hierarchic categories separately for weekend and weekdays. The duration of time spent on the Internet using the mobile phone, subsequently referred to as Online (MP), for example was assessed via the item "How much time do you spend actively online using your mobile phone?" and rated on five categories. The lowest category hereby was "never or less than 10 minutes per day" and the highest "more than 1.5 hours per day". In addition, some of the question were based on a self-estimated duration like playing games (Gaming) which was asked about with the item "For how long do you engage in PC/online games or video console playing per day?" followed by a free 
space in which the participant could write down an open answer in minutes per day. The complete list of included items and their answering schemes is displayed in the first two columns of table 1.

Table 1: Overview over the questionnaire items entering the latent class analysis and their original scoring scheme (Columns one and two). For latent class analysis the variables had to be categorized. Columns three to five show the number of participants in the respective category and their respective mean value on the numeric score derived by the original questionnaire items.

\begin{tabular}{|c|c|c|c|c|}
\hline $\begin{array}{l}\text { Usetype } \\
\text { Original questionnaire item }\end{array}$ & Original scoring & Category & $N$ & Mean(SD) \\
\hline $\begin{array}{l}\text { Calls (MP)* } \\
\text { "For how long do you use your mobile phone for calling per } \\
\text { day?" }\end{array}$ & $\begin{array}{l}\text { Open answer } \\
\text { (minutes/day) }\end{array}$ & $\begin{array}{l}\text { Low } \\
\text { Medium } \\
\text { High }\end{array}$ & $\begin{array}{l}281 \\
278 \\
284\end{array}$ & $\begin{array}{l}1.3(1.2) \\
8.1(2.9) \\
46.2(44.8)\end{array}$ \\
\hline $\begin{array}{l}\text { Test messages* } \\
\text { "How many short messages do you sent per day via mobile } \\
\text { phone?" (separately for SMS and. Instant messenger apps) }\end{array}$ & $\begin{array}{l}6 \text { hierarchical } \\
\text { categories } \\
\text { (frequency/day) }\end{array}$ & $\begin{array}{l}\text { Low } \\
\text { Medium } \\
\text { High }\end{array}$ & $\begin{array}{l}161 \\
274 \\
411\end{array}$ & $\begin{array}{l}2.1(1.5) \\
17.5(10.2) \\
55.2(9.2)\end{array}$ \\
\hline $\begin{array}{l}\text { Online on MP* } \\
\text { "How much time do you spend actively online on your } \\
\text { mobile phone?" }\end{array}$ & $\begin{array}{l}5 \text { hierarchical } \\
\text { categories } \\
\text { (minutes/day) }\end{array}$ & $\begin{array}{l}\text { Low } \\
\text { Medium } \\
\text { High }\end{array}$ & $\begin{array}{l}243 \\
303 \\
302\end{array}$ & $\begin{array}{l}5.5(9.0) \\
50.0(26.5) \\
103.1(11.6)\end{array}$ \\
\hline $\begin{array}{l}\text { Calls (landline)* } \\
\text { "How long on average are you conducting phone calls via a } \\
\text { cordless phone at home?" }\end{array}$ & $\begin{array}{l}5 \text { hierarchical } \\
\text { categories } \\
\text { (minutes/day }\end{array}$ & $\begin{array}{l}\text { Low } \\
\text { Medium } \\
\text { High }\end{array}$ & $\begin{array}{l}450 \\
143 \\
257\end{array}$ & $\begin{array}{l}2.1(0.9) \\
5.6(1.5) \\
17.6(11.3)\end{array}$ \\
\hline $\begin{array}{l}\text { Gaming* } \\
\text { "How much time on average do you spend gaming on a PC } \\
\text { Laptop / tablet/TV(video console)" }\end{array}$ & $\begin{array}{l}\text { Open answer } \\
\text { (minutes/day) }\end{array}$ & $\begin{array}{l}\text { Low } \\
\text { Medium } \\
\text { High }\end{array}$ & $\begin{array}{l}242 \\
398 \\
206\end{array}$ & $\begin{array}{l}0.0(0.0) \\
22.0(15.8) \\
122.7(52.9)\end{array}$ \\
\hline $\begin{array}{l}\text { Music } \\
\text { „Do you use your mobile phone for listening to music?" }\end{array}$ & $\begin{array}{l}5 \text { hierarchical } \\
\text { categories } \\
\text { (minutes/day) }\end{array}$ & $\begin{array}{l}\text { Low } \\
\text { Medium } \\
\text { High }\end{array}$ & $\begin{array}{l}198 \\
308 \\
302\end{array}$ & $\begin{array}{l}2.8(2.5) \\
35.0(0.0) \\
122.7(52.9)\end{array}$ \\
\hline $\begin{array}{l}\text { Social Network Sites } \\
\text { Do you have an account at the social network X? If yes, how } \\
\text { frequently do you log in?" (separately for } X=6 \text { social } \\
\text { network platforms) }\end{array}$ & $\begin{array}{l}5 \text { hierarchical } \\
\text { categories } \\
\text { (login/day) }\end{array}$ & $\begin{array}{l}\text { Low } \\
\text { Medium } \\
\text { High }\end{array}$ & $\begin{array}{l}150 \\
372 \\
317\end{array}$ & $\begin{array}{l}0.0(0.0) \\
0.9(0.5) \\
6.1(2.8)\end{array}$ \\
\hline $\begin{array}{l}\text { MPPUS-10 } \\
\text { Screening tool for problematic mobile phone use in } \\
\text { adolescents. } 10 \text { questions based on symptoms of behavioral } \\
\text { addictions. }\end{array}$ & $\begin{array}{l}\text { Questionnaire score } \\
\text { (range10-100) }\end{array}$ & $\begin{array}{l}\text { Low } \\
\text { Medium } \\
\text { High }\end{array}$ & $\begin{array}{l}270 \\
273 \\
305\end{array}$ & $\begin{array}{l}15.3(3.6) \\
28.3(4.0) \\
48.7(11.0)\end{array}$ \\
\hline $\begin{array}{l}\text { PC use } \\
\text { "How much time do you spend using device } X \text { per day" } \\
\text { (separately for three devices X =PC, Table, Laptop) }\end{array}$ & $\begin{array}{l}\text { Open answer } \\
\text { (minutes/day) }\end{array}$ & $\begin{array}{l}\text { Low } \\
\text { Medium } \\
\text { High }\end{array}$ & $\begin{array}{l}273 \\
291 \\
283\end{array}$ & $\begin{array}{l}10.9(7.4) \\
45.0(12.7) \\
159.2(99.2)\end{array}$ \\
\hline $\begin{array}{l}\text { MP expenses } \\
\text { "How high are your monthly expenses for your mobile } \\
\text { phone (if you have a fixed contract expenses should include } \\
\text { the basic fee)?" }\end{array}$ & $\begin{array}{l}6 \text { hierarchical } \\
\text { categories } \\
\text { (CHF/month) }\end{array}$ & $\begin{array}{l}\text { Low } \\
\text { Medium } \\
\text { High }\end{array}$ & $\begin{array}{l}316 \\
224 \\
231\end{array}$ & $\begin{array}{l}5.5(0.0) \\
20.5(5.0) \\
46.5(9.9)\end{array}$ \\
\hline $\begin{array}{l}\text { MP at night } \\
\text { „Do you switch off your mobile phone during night?" }\end{array}$ & $\begin{array}{l}4 \text { hierarchical } \\
\text { categories } \\
\text { (never to always) }\end{array}$ & $\begin{array}{l}\text { On } \\
\text { Off }\end{array}$ & $\begin{array}{l}414 \\
427\end{array}$ & \\
\hline
\end{tabular}

* Questions asked separately for weekdays end weekend 


\subsubsection{Problematic mobile phone use}

To measure addictive tendencies regarding mobile phone use the MPPUS-10 was administered. The questionnaire consists of 10 items using a ten point Likert-scale covering different aspects of problematic device use namely loss of control, withdrawal, craving, negative life consequences and peer dependence. Internal consistency of the questionnaire is good (Cronbach's Alpha $=0.85)$. The questionnaire score was used as variable entering the latent class analysis (MPPUS-10).

\subsubsection{KIDSCREEN}

The KIDSCREEN-52 (Ravens-Sieberer et al., 2008; The KIDSCREEN Group Europe, 2006) is a standardized questionnaire measuring the health related quality of adolescents' life on ten dimensions named Physical Well-being (5 items), Psychological Well-being (6 items), Moods and Emotions (7 items), Self-Perception (5 items), Autonomy (5 items), Parent Relation and Home Life (6 items), Social Support and Peers (6 items), School Environment (6 items), Social Acceptance (3 items) and Financial Resources (3 items) answered on 5-point Likert scales. For easier interpretation of the results the subscale scores are transferred into T-values with mean values of 50 and standard deviations of 10. Transformation is conducted via an algorithm derived from the original European KIDSCREEN sample of children and adolescents from 13 European countries. Higher values indicate more well-being on the respective scale (Ravens-Sieberer et al., 2008). In the same sample the internal consistency measured with Cronbach's alpha ranged from 0.77 to 0.89 and the test-retest stability ranged from 0.56 to 0.77 for the ten dimensions. The internal consistency in the HERMES sample for the ten scales was comparable with alpha values ranging between 0.77 (Self-Perception) and 0.89 (Psychological Well-Being).

\section{Statistical analysis}

Data analysis consisted of two steps. First a latent class analysis was performed to identify subgroups of media use patterns. Afterwards associations between the identified classes and the KIDSCREEN subscales were investigated applying multivariable linear regression models. 


\subsection{Latent class analysis}

Latent class analysis is a method to classify a population into meaningful subgroups showing distinct patterns of item response probabilities on a set of predefined variables. For each individual (observation) a posterior probability for belonging to one class is provided.

Identifying the number of classes is the critical step of the analysis. In this study we considered models consisting of one to seven latent classes. The overall fit of the models was compared via the samplesize adjusted Bayesian Information Criterion (SABIC), the Akaike's information criterion (AIC) and the Bozdogan's criterion (consistent Akaike's information criterion; CAIC). Since the SABIC is a trustworthy criterion of model fit it was our primary goodness of fit index for determining the number of classes . However, an equally important criterion is that the final model-solution consists of theoretically meaningful classes.

After model selection covariates (e.g. gender) may be included in the analysis. If so, the posterior probabilities are conditioned on their values (being female/male). We decided to include two covariates, gender and belonging to one of the two subsamples (subsequently referred to as sample 2012/2013 and sample 2014/2015, respectively) because both might strongly impact media use in adolescents.

Finally, a post-hoc analysis of the final class solution was conducted regarding their ability to classify individuals with posterior probabilities of at least $80 \%$ and $90 \%$.

The eleven variables included in the LCA are presented in more detail in section 2.2.1. and displayed in table 1. Since latent class analysis cannot be applied to numeric variables, the variables were categorized into low, medium and high. An exception was MP at night which was dichotomized ("switched off" vs. "switched on")

LCA was executed using the Penn State University Methodology Center LCA Stata Plugin

\subsection{Multivariable linear regression models}

To investigate the associations of the class-memberships and health related quality of life, multivariable linear regression models were computed using the KIDSCREEN subscale scores as 
outcome variables. The class affiliation derived by the LCA was included as categorical explanatory variable with the class showing the lowest use as reference category. Coefficients were obtained via non-parametric bootstrapping (resampling rate: 1000) to account for the non-normal data distribution. All models were adjusted for sex, age, nationality, school-level and education of the parents. Missing values in the variable educational level of the parents (240 missing values) were imputed using the most common education level stratified over adolescents' school level.

Statistical analyses were carried out using STATA version 14.0 (StataCorp, College Station, TX, USA).

\section{Results}

\subsection{Sample}

A total of 895 adolescents participated in the study from which 439 (49.1\%) were assessed in the first and $456(50.9 \%)$ in the second sampling period respectively. $45(5.0 \%)$ reported not to own a mobile phone and were therefore excluded from the analysis. Of the remaining 850 participants $753(88.6 \%)$ were smartphone users. The mean age was 14.1 years (ranging from 10.4 to 17.0$)$ and more girls (484; $56.9 \%)$ than boys $(366 ; 43.1 \%)$ participated in the study.

\subsection{Latent class analysis}

The fit indices for model comparison up to the seven-class solution based on the ML-algorithm are displayed in table 2 .

Table 2: Goodness of fit indices AIC (Akaike's Information Criterion), SABIC (sample-size adjusted Bayesian Information Criterion) and CAIC (Bozdogan's Criterion) for the one to seven class solutions. Note that lower values indicate better model fit.

\begin{tabular}{lccc}
\hline Class & AIC & SABIC & CAIC \\
\hline 1 & 7977.836 & 8010.796 & 8098.486 \\
2 & 6915.921 & 6983.411 & 7162.967 \\
3 & 6678.418 & 6780.438 & 7051.859 \\
4 & 6605.126 & 6741.979 & 7104.962 \\
5 & 6560.872 & 6731.951 & 7187.103 \\
6 & 6530.433 & 6736.041 & 7283.058 \\
7 & 6513.931 & 6754.069 & 7392.952 \\
\hline
\end{tabular}


The three-class and the five-class solution were considered as the final model. The three-class solution showed the lowest CAIC but the SABIC goodness of fit indicator favoured the five-class solution, we preferred this final model (Nylund et al., 2007; Tofighi et al., 2008). Except of the fit indices this decision was based on our aim to explore qualitatively different classes of use and not to divide the sample simply into high, medium and low use as suggested by a three class solution. The three class solution split the sample in groups containing 50.1\% (medium use), $27.7 \%$ (high use) and $22.2 \%$ (low use) (data not shown), the five-class solution in $28.3 \%, 9.8 \%, 19.6 \%, 15.3 \%$ and $27.1 \%$ of the participants, respectively. The main difference of the five-class solution was the split of medium use into three smaller classes leading to more distinct use patterns.

After inclusion of the covariates sample and gender the five classes identified were named Gaming , Medium Use, Low Use, Call Preference and High Social Use. The naming was based on the item response probabilities of the respective classes. The Gaming class for example had a particular high probability to score in the category "high" for the variables "Gaming" and "PC-use". A complete overview of the item response probabilities is displayed in table 3. 
Table 3: Item response probabilities for the different categories of the 10 media use variables and of MP at night in the five latent classes

\begin{tabular}{|c|c|c|c|c|c|c|}
\hline \multirow[b]{2}{*}{ Type of Use } & \multirow[b]{2}{*}{ Category } & \multicolumn{5}{|c|}{ Class } \\
\hline & & Low Use & $\begin{array}{l}\text { Medium } \\
\text { Use }\end{array}$ & Gaming & $\begin{array}{c}\text { Call } \\
\text { Preference }\end{array}$ & $\begin{array}{c}\text { High Social } \\
\text { Use }\end{array}$ \\
\hline \multirow[t]{3}{*}{ Calls (MP) } & Low & 0.54 & 0.41 & 0.41 & 0.09 & 0.18 \\
\hline & Medium & 0.34 & 0.41 & 0.35 & 0.23 & 0.29 \\
\hline & High & 0.12 & 0.17 & 0.24 & 0.68 & 0.53 \\
\hline \multirow{3}{*}{$\begin{array}{l}\text { Text } \\
\text { messages }\end{array}$} & Low & 0.80 & 0.02 & 0.00 & 0.13 & 0.01 \\
\hline & Medium & 0.20 & 0.55 & 0.49 & 0.44 & 0.01 \\
\hline & High & 0.00 & 0.42 & 0.50 & 0.42 & 0.99 \\
\hline \multirow[t]{3}{*}{ Online on MP } & Low & 0.77 & 0.26 & 0.22 & 0.21 & 0.00 \\
\hline & Medium & 0.10 & 0.51 & 0.53 & 0.35 & 0.32 \\
\hline & High & 0.13 & 0.23 & 0.26 & 0.44 & 0.68 \\
\hline \multirow{3}{*}{$\begin{array}{l}\text { Calls } \\
\text { (landline) }\end{array}$} & Low & 0.48 & 0.61 & 0.71 & 0.24 & 0.58 \\
\hline & Medium & 0.22 & 0.17 & 0.15 & 0.19 & 0.12 \\
\hline & High & 0.30 & 0.22 & 0.15 & 0.57 & 0.30 \\
\hline \multirow[t]{3}{*}{ Gaming } & Low & 0.22 & 0.38 & 0.00 & 0.21 & 0.42 \\
\hline & Medium & 0.56 & 0.62 & 0.04 & 0.53 & 0.40 \\
\hline & High & 0.23 & 0.00 & 0.96 & 0.26 & 0.18 \\
\hline \multirow[t]{3}{*}{ Music } & Low & 0.70 & 0.21 & 0.11 & 0.11 & 0.00 \\
\hline & Medium & 0.22 & 0.50 & 0.53 & 0.34 & 0.26 \\
\hline & High & 0.08 & 0.29 & 0.35 & 0.55 & 0.74 \\
\hline \multirow{3}{*}{$\begin{array}{l}\text { Social } \\
\text { networks }\end{array}$} & Low & 0.38 & 0.20 & 0.16 & 0.10 & 0.04 \\
\hline & Medium & 0.60 & 0.49 & 0.34 & 0.81 & 0.06 \\
\hline & High & 0.03 & 0.32 & 0.49 & 0.08 & 0.90 \\
\hline \multirow[t]{3}{*}{ MPPUS-10 } & Low & 0.78 & 0.35 & 0.27 & 0.15 & 0.03 \\
\hline & Medium & 0.16 & 0.46 & 0.46 & 0.36 & 0.21 \\
\hline & High & 0.06 & 0.19 & 0.27 & 0.49 & 0.76 \\
\hline \multirow[t]{3}{*}{ PC use } & Low & 0.25 & 0.53 & 0.14 & 0.09 & 0.38 \\
\hline & Medium & 0.44 & 0.33 & 0.22 & 0.42 & 0.29 \\
\hline & High & 0.31 & 0.14 & 0.64 & 0.48 & 0.33 \\
\hline \multirow[t]{3}{*}{ MP expenses } & Low & 0.72 & 0.40 & 0.31 & 0.17 & 0.20 \\
\hline & Medium & 0.18 & 0.27 & 0.29 & 0.40 & 0.23 \\
\hline & High & 0.10 & 0.33 & 0.40 & 0.43 & 0.57 \\
\hline \multirow[t]{2}{*}{ MP at night } & switched off & 0.65 & 0.62 & 0.55 & 0.29 & 0.31 \\
\hline & switched on & 0.35 & 0.38 & 0.45 & 0.71 & 0.69 \\
\hline
\end{tabular}


The post-hoc analysis of the class membership probabilities affirmed $66.9 \%$ of individuals being assigned to a certain class with a certainty of $>0.9$ and $78.8 \%$ with $>0.8$, respectively for the five class solution (data not shown). For further analysis all participants were assigned to the class for which they showed the highest individual membership probability.

Inclusion of the covariates gender and sample revealed that participants' class membership was highly dependent on being male or female and belonging to sample 2012/2013 or sample 2014/2015. Table 4 shows the distributions of the five classes on the covariates and demographic variables. 
Table 4: Descriptive statistics of the total sample and the five classes on the demographic variables adjusted for in the multivariable regression models.

\begin{tabular}{|c|c|c|c|c|c|c|}
\hline & Total & Low Use & Medium Use & Gaming & Call Preference & High Social Use \\
\hline Total & 850 & $171(20 \%)$ & $237(28 \%)$ & $99(12 \%)$ & $125(15 \%)$ & $218(25 \% \%)$ \\
\hline \multicolumn{7}{|l|}{ Gender } \\
\hline Female & $484(56.9 \%)$ & $103(60.2 \%)$ & $127(53.6 \%)$ & $1(1.0 \%)$ & $92(73.6 \%)$ & $161(73.9 \%)$ \\
\hline Male & $366(43.1 \%)$ & $68(39.8 \%)$ & $110(46.4 \%)$ & $98(99.0 \%)$ & $33(26.4 \%)$ & $57(26.1 \%)$ \\
\hline \multicolumn{7}{|l|}{ Sample } \\
\hline Sample 1 (2012-2013) & $412(48.5 \%)$ & $168(98.3 \%)$ & $53(22.4 \%)$ & $40(40.4 \%)$ & $124(99.2 \%)$ & $27(12.4 \%)$ \\
\hline Sample 2 (2014-2015) & $438(51.5 \%)$ & $3(1.7 \%)$ & $184(77.6 \%)$ & $59(59.6 \%)$ & $1(0.8 \%)$ & $191(87.6 \%)$ \\
\hline Age in years (min-max) & 14.1 & $13.7(12.1-18.8)$ & $13.9(10.4-17.0)$ & $14.1(12.2-16.4)$ & $14.1(12.3-16.7)$ & $14.2(12.5-16.8)$ \\
\hline \multicolumn{7}{|l|}{ Nationality } \\
\hline Swiss & $642(75.8 \%)$ & $144(84.2 \%)$ & $189(79.7 \%)$ & $76(77.6 \%)$ & $92(73.6 \%)$ & $141(65.3 \%)$ \\
\hline Swiss and foreign & $118(13.9 \%)$ & 19 (11.1\%) & $31(13.1 \%)$ & $10(10.2 \%)$ & $21(16.8 \%)$ & 37 (17.1\%) \\
\hline Foreign & $87(10.3 \%)$ & $8(4.7 \%)$ & $17(7.2 \%)$ & $12(12.2 \%)$ & $12(9.6 \%)$ & $38(17.6 \%)$ \\
\hline \multicolumn{7}{|l|}{ Schoollevel } \\
\hline Secondary school level C & $169(20.1 \%)$ & $21(12.5 \%)$ & $33(13.9 \%)$ & $24(24.2 \%)$ & $36(29.5 \%)$ & $55(25.4 \%)$ \\
\hline Secondary school level B & $237(28.1 \%)$ & $32(19.0 \%)$ & $71(30.0 \%)$ & $36(36.4 \%)$ & $30(24.6 \%)$ & $68(31.3 \%)$ \\
\hline Secondary school level A & $265(31.4 \%)$ & $63(37.5 \%)$ & $76(32.1 \%)$ & $20(20.2 \%)$ & $40(32.8 \%)$ & $66(30.4 \%)$ \\
\hline High school level & $172(20.4 \%)$ & $52(31.0 \%)$ & $57(24.0 \%)$ & $19(19.2 \%)$ & $16(13.1 \%)$ & $28(12.9 \%)$ \\
\hline \multicolumn{7}{|c|}{ Highest education of the parents } \\
\hline Training School & $387(45.5 \%)$ & $69(40.4 \%)$ & $95(40.1 \%)$ & $47(47.5 \%)$ & 95 (40.1\%) & $111(50.9 \%)$ \\
\hline High School & $176(20.7 \%)$ & $18(10.5 \%)$ & $60(25.3 \%)$ & $18(18.2 \%)$ & $60(25.3 \%)$ & $65(29.8 \%)$ \\
\hline University / college & $287(33.8 \%)$ & $84(49.1 \%)$ & $82(34.6 \%)$ & $34(34.3 \%)$ & $82(34.6 \%)$ & $42(19.3 \%)$ \\
\hline
\end{tabular}




\subsubsection{Latent class media use profiles}

A graphical illustration of the five media use patterns is displayed in figure 1.

Figure 1: Mean values of the eleven different item scores expressed as a fraction of the respective overall mean across the five latent classes. The class mean/total ratio was calculated on the real values of the non-categorized variables by dividing the class mean by the simple mean.
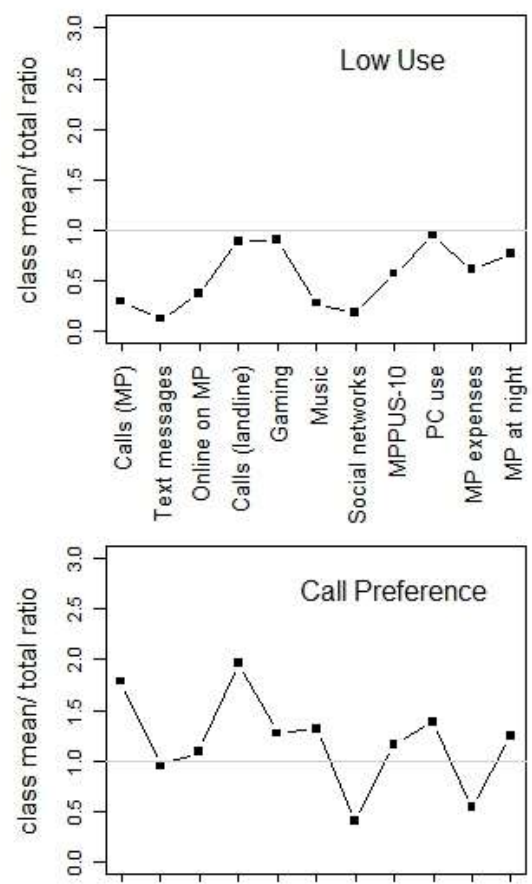

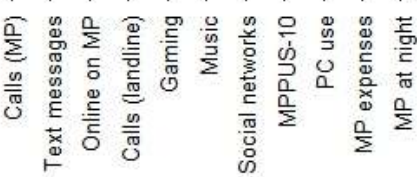
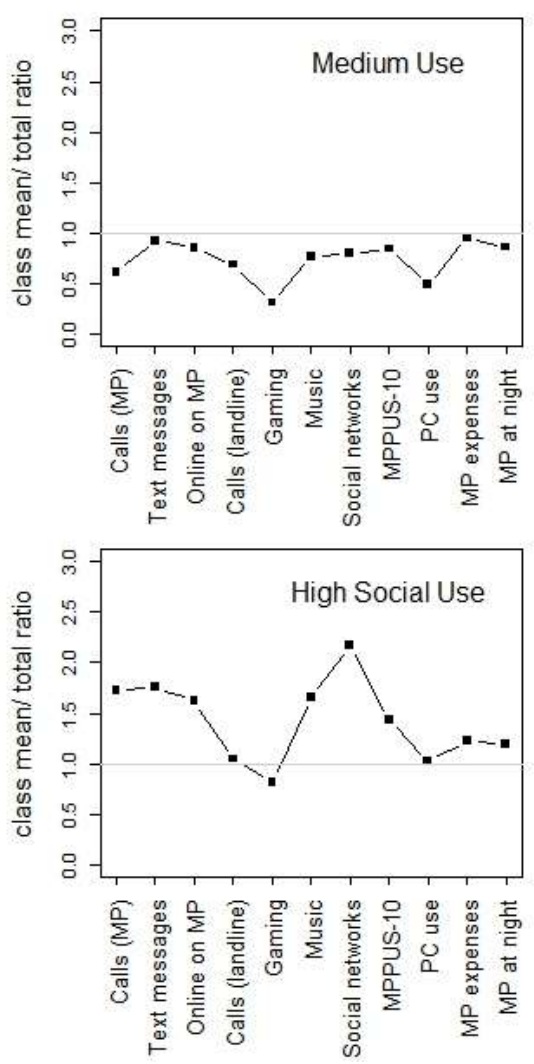

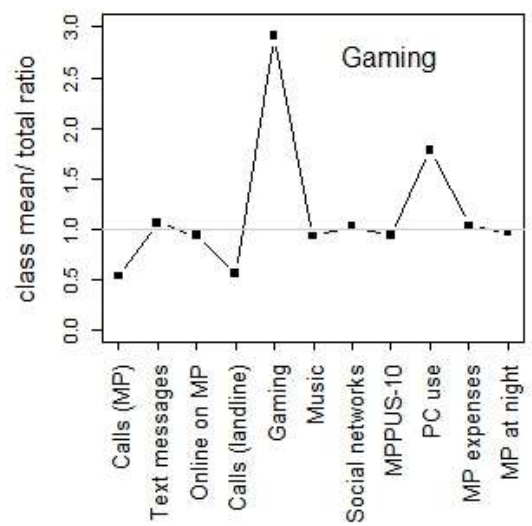


The Low Use class showed the least frequent media use. More than $70 \%$ of the class members scored in the lowest category for eight (calls (MP), calls (landline), text messages, online on MP, music, MPPUS-10 and MP expenses, MP at night) out of the eleven use variables. Further, the penetration rate of smartphones was low in that group ( $51.8 \%$ compared to $97.8 \%$ in the remaining sample). Interestingly, almost the whole group belonged to sample 2012/2013.

The Medium Use class showed a rather average pattern of media use. In most of the smartphone related use variables the major part of the group scored in the medium category. In contrast to the Low Use class, they had a higher rate of participants of sample 2014/2015.

$96 \%$ of the Gaming class which consisted almost exclusively of boys reported high use on the variable gaming. Their actual mean gaming duration was three times higher than in the sample overall. In addition they spent twice as much time on PC or tablet. Otherwise their media use was low to average for different usage variables.

The Call Preference class showed a rather high media use except use of social networks. Unlike the other classes, the group seemed to favor phone calls (on mobile phone as well as landline phone) over texting. The majority of the class scored high in both call variables. Similarly to the Low Use class the fourth class consisted mainly of participants investigated in sample 2012/2013 but the proportion of smartphone users was still high (93.6\%).

The High Social Use class consisted mainly of girls from sample 2014/2015. Compared to the other classes the group showed the highest use of all variables related to social communication purposes on a smartphone such as use of social network sites, text messages or time spent online on the device. The class also showed the highest values on the MPPUS-10. The only variable below average was gaming.

\subsection{Multivariable regression models}

After adjustment for various confounders, significant differences in the scores of six out of ten KIDSCREEN health related quality of life subscales were found among the five classes (Table 5). 
Table 5: Adjusted mean scores and 95\% confidence intervals for the five classes on the 10 KIDSCREEN scales.

\begin{tabular}{|c|c|c|c|c|c|c|c|c|c|c|c|c|c|}
\hline \multirow[b]{2}{*}{ KIDSCREEN subscale } & \multirow[b]{2}{*}{$\mathrm{N}$} & \multirow[b]{2}{*}{ chi2 } & \multirow[b]{2}{*}{$\begin{array}{c}\mathrm{p}- \\
\text { value }\end{array}$} & \multicolumn{2}{|c|}{ Low Use } & \multicolumn{2}{|c|}{ Medium Use } & \multicolumn{2}{|c|}{ Gaming } & \multicolumn{2}{|c|}{ Call Preference } & \multicolumn{2}{|c|}{ High Social Use } \\
\hline & & & & score* & $95 \% \mathrm{Cl}$ & score* & $95 \% \mathrm{Cl}$ & score* & $95 \% \mathrm{Cl}$ & score* & $95 \% \mathrm{Cl}$ & score* & $95 \% \mathrm{Cl}$ \\
\hline Physical Well-being & 838 & 18.77 & 0.002 & 48.1 & $(46.4 ; 49.8)$ & 52.0 & $(50.8 ; 53.2)$ & 49.2 & $(47.2 ; 51.3)$ & 47.8 & $(45.9 ; 49.6)$ & 50.3 & $(48.8 ; 51.7)$ \\
\hline Psychological Well-being & 837 & 3.92 & 0.561 & 52.1 & $(50.4 ; 53.8)$ & 52.7 & $(51.4 ; 54.0)$ & 51.4 & $(49.4 ; 53.4)$ & 51.8 & $(45.0 ; 53.7)$ & 52.4 & $(50.8 ; 53.9)$ \\
\hline Moods and Emotions & 835 & 30.03 & $>0.001$ & 55.1 & $(53.3 ; 57.0)$ & 52.1 & $(50.7 ; 53.4)$ & 51.9 & $(49.7 ; 54.2)$ & 51.3 & $(49.5 ; 50.7)$ & 49.1 & $(47.5 ; 50.7)$ \\
\hline Self-Perception & 837 & 21.41 & $>0.001$ & 51.8 & $(50.3 ; 53.3)$ & 50.8 & $(49.7 ; 52.0)$ & 49.4 & $(47.4 ; 51.4)$ & 49.9 & $(48.2 ; 51.5)$ & 48.0 & $(46.7 ; 49.3)$ \\
\hline Autonomy & 835 & 7.27 & 0.201 & 50.8 & $(49.4 ; 52.3)$ & 50.2 & $(48.9 ; 51.4)$ & 49.4 & $(47.5 ; 51.3)$ & 51.0 & $(49.2 ; 52.8)$ & 50.2 & $(48.9 ; 51.6)$ \\
\hline Parent Relations and Home Life & 833 & 21.13 & $>0.001$ & 53.3 & $(51.7 ; 54.9)$ & 51.9 & $(50.7 ; 53.1)$ & 50.4 & $(48.4 ; 52.3)$ & 52.4 & $(50.5 ; 54.3)$ & 48.6 & $(47.2 ; 50.0)$ \\
\hline Financial Ressources & 820 & 8.51 & 0.130 & 55.4 & $(54.1 ; 56.8)$ & 55.4 & $(54.4 ; 56.3)$ & 54.6 & $(54.0 ; 56.2)$ & 54.2 & $(52.6 ; 55.8)$ & 53.6 & $(52.4 ; 54.9)$ \\
\hline Social Support and Peers & 835 & 27.78 & $>0.001$ & 48.5 & $(46.9 ; 50.0)$ & 51.5 & $(50.3 ; 52.8)$ & 49.0 & $(47.1 ; 50.8)$ & 51.5 & $(49.6 ; 53.4)$ & 53.8 & $(52.4 ; 55.3)$ \\
\hline School Environment & 833 & 16.01 & 0.007 & 52.7 & $(51.3 ; 54.0)$ & 51.8 & $(50.7 ; 52.8)$ & 51.0 & $(49.3 ; 52.7)$ & 50.9 & $(49.4 ; 52.5)$ & 49.3 & $(48.2 ; 50.5)$ \\
\hline Social Acceptance & 835 & 3.15 & 0.677 & 51.3 & $(49.6 ; 53.0)$ & 51.6 & $(50.3 ; 52.9)$ & 50.8 & $(48.8 ; 52.8)$ & 52.1 & $(50.0 ; 54.1)$ & 51.7 & $(50.2 ; 53.2)$ \\
\hline
\end{tabular}

$*$ all scores adjusted for gender, age, investigation phase, nationality, school level and education of the

parents

$\$$ p-value for group differences calculated by likelihood ratio test 
In general, two classes appeared to diverge most amongst the scores. The Low Use class and the High Social Use class were on the upper and lower extremes, respectively, of the subscales Moods and Emotions (mean adjusted scores: 55.1 (95\%CI: 53.8; 57.0) vs. 49.1 (47.5; 50.7) ), Self-Perception (51.8 (50.3; 53.3) vs. 48.0(46.7; 49.28), Parent Relation and Home Life (53.3 (51.7; 54.9) vs. 48.6 $(47.2 ; 50.0))$ and School Environment $(52.7(51.3 ; 54.0)$ vs. $49.3(48.2 ; 50.7))$. Thus, of all classes, the High Social Use class reported lowest levels of positive feelings, self-esteem and most problems at home and in school whereas the Low Use class felt most comfortable in those domains. However, the picture was reversed on the subscale Social Support and Peers. Here the High Social Use class showed the highest and the Low Use class the lowest score $(53.8(52.4 ; 55.3)$ vs. $48.5(47.0 ; 50.0))$. In addition, the Medium Use class scored highest on the Physical Well-being subscale while the Low Use class showed the lowest score on that scale $(52.0(50.8 ; 53.2)$ vs. $48.1(46.4 ; 49.8))$. For the other four scales (Psychological Well-being, Autonomy, Financial Resources, Social Acceptance) no significant differences between the classes were found

\section{Discussion}

\subsection{Latent class media use profiles}

Through the latent class analysis five distinct groups differing amongst eleven different media use variables were identified. The inclusion of gender and the subsample as covariates showed meaningful differences between the classes.

Male gender was most prominent in the Gaming group which is in line with previous research on (online) gaming (Kuss et al., 2012). Interestingly the Gaming group was most equally distributed amongst the two subsamples. The reason for this might be that online gaming has evolved long before Smartphones and so the class might not have been affected by recent technological changes in the telecommunication industry.

The Medium Use class and the Low Use class showed the lowest but somehow diverging levels of media use. The Medium Use class used mainly the mobile phone for social communication while Low Use rather engaged in gaming or used other media. Most of the Medium Use class was part of sample 
2014/2015. In contrast almost the whole Low Use class was investigated in sample 2012/2013. At that time Smartphones were less frequently used. Indeed, the smartphone penetration was lowest in the Low Use class (51.8\% compared to $97.8 \%$ in the remaining sample). It seems likely that these two classes depict to some extend the technological switch from "old fashioned" mobile phones to Smartphones in between the sampling times.

A clear effect of both covariates was observed in the two classes going along with rather high media use, Call Preference and High Social Use. Both groups consisted from a far higher proportion of girls which is in line with previous knowledge (Nesi et al., 2015; Shin et al., 2015; van Deursen et al., 2015). While Call Preference recruited its members mainly from sample 2012/2013 High Social Users were more likely to belong to sample 2014/2015. Call Preference was mainly characterized by higher levels of calling (mobile phone and landline) while High Social Use was marked by heavy use of texting and social networks. This might mirror the more easy and cheap use of web based social messenger application in sample 2014/2015 through the broader availability of WiFi and data flatrates included in mobile phone contracts.

\subsection{Associations with the KIDSCREEN}

In general, health related quality of life differed most amongst the High Social Use class and the Low Use class whereby the High Social Use class showed less well-being on most of the scales but the best connections with peers. The Call Preference and Gaming class lied between these two extreme categories but also explained part of the outcome variances.

\subsubsection{Negative affectivity, self-perception and adolescents media use}

The High Social Use class differed most from the Low Use class in the KIDSCREEN subscales Moods and Emotions and Self-Perception. These findings are supported by recent studies linking online social communication to depressive symptoms and low self-esteem (Demirci et al., 2015; Ehrenberg et al., 2008; Thomée et al., 2012; Yen et al., 2009). The question of causality here is still discussed and for both directions there are reasonable arguments. On the one hand, individuals with initial high levels of depression and/or low levels of self-esteem may perceive online social 
communication via social network sites or instant messengers as a possibility to gain social support on a lower threshold and to relief themselves from negative feelings through the ease of online selfdisclosure (Dolev-Cohen et al., 2013; Ellison et al., 2007; Oh et al., 2014; Selfhout et al., 2009; Steinfield et al., 2008; Zhang et al., 2011). On the opposite using social network sites and instant messengers might heighten levels of depression and lessen life satisfaction and self-esteem. Usually, this is explained by dysfunctional social comparisons on social media platforms (Feinstein et al., 2013; Tandoc et al., 2015).

\subsubsection{A poststructuralist integration of online social communication}

Another possible mechanism which was not yet examined to the best of our knowledge relates to language perception as well as adolescents' psychosocial development and implicit learning processes. Poststructuralists like Foucault claim that the oral and written speech one is surrounded by determines how one perceives his or her environment (Foucault, 2002). Besides, our emotional and intellectual perception of speech is socioculturally determined (Barrett et al., 2007) even influencing related neurological processes (Wager et al., 2008). The individual perception of the environment is thus dependent from the linguistic frame this individual is moving in.

We can apply this thought to adolescents' media use. Online social communication facilitates selfdisclosure via web forums, on online social media platforms via private postings or through the heavy use of instant messaging applications like WhatsApp to rapidly exchange short messages transporting delicate emotional contents (Trepte et al., 2013). These processes of frequent verbal expression of private emotional contents might often be additionally positively affirmed by "likes" leading to implicit learning processes (Kisyovska et al., 2015).

From a poststructuralist view, permanent exposition to and composing of emotional posts and messages may determine how media-prone adolescents perceive, think about and act within their social environment. It is thinkable that the higher exposure to private linguistically transmitted emotional contents in a young age might have an impact on the individual psychosexual development fostering earlier mature and "adult-like" behaviour. In our sample such processes would mainly be seen in the High Social Use class. The high scores on the Moods and Emotions scale could then be 
partly an artifact due to an ongoing paradigmatic change to think and perceive emotions facilitated by the frequent use of social networks and instant messengers.

Subsuming both ideas more research should be done on the emotional contents of online communication, reinforcement processes and their potential to influence the speech and perception of adolescents. Neuropsychological studies on emotional affectivity and learning could shed light onto those complex interactions.

\subsubsection{Social environment, (online) social capital and media use}

It is known that adolescents' health is strongly dependent from their social status within society and their proximal social environment. Amongst the most protective factors are safe and supportive families and schools as well as positive and supportive peers (Viner et al., 2012). The High Social Use class showed least satisfaction at home (Parent Relation and Home Life) and less connectedness to school and teachers (School Environment) both particularly contrasted by the Low Use class. Nevertheless, the High Social Use class seemed to have better relationships to peers (Social Support and Peers) than the Low Use class.

These findings indicate that media use might be a mediating factor in the psychosexual development during adolescence there one struggles in defining an own social and yet individual identity in society (Erikson, 1994). These processes are accompanied by social comparisons, the need for belonging, an increasing sensitivity for one's own feelings and emotions and the urge to gain autonomy from parents . In adolescents, the use of smartphones and social network platforms for social communication bear several advantages compared to face-to-face interaction. In a qualitative approach Irish teenagers emphasized staying in intimate contact and sharing the best kept secrets with friends, hiding from the parents, finding help for emotional struggles on a lower threshold or the increased control over written compared to spoken language as motives for online communication (Rice, 2013). In this way media use increases adolescents' social capital which is known as a positive resource resulting from sociability and interpersonal relationships (Bourdieu, 2011) and has been linked to online social communication (Bian et al., 2015; Ellison et al., 2007; Steinfield et al., 2008). 
Although social capital is known as a protective factor in terms of mental and physical health it remains unclear if its positive effects are comparable if gained through online versus face-to-face interactions. In addition, adolescents' perception of meaningful peer contacts might be biased by social desirability and the wish of self-enhancement. Apart from this positive resource, media use could foster social separation through group formations whereby the messaging frequency or the number of Facebook friends might be important social ranking indicators. That might produce sublime feelings of oneself and the in-group through the perception of being popular and the degradation of others . The wish to belong to the "cool" kids in this way might coincidentally trigger compulsive or even risky smartphone and online behavior like Cyberbullying or Sexting.

Nevertheless, it seems likely that nowadays children "naturally" increase their smartphone and social media use while turning towards adolescence. The use of smartphones and the internet for social communication might help them to approach the challenges in their psychosexual development they have to go through until conquering adulthood (e.g. gaining autonomy from parents, dealing with intimate thoughts etc.). In our results, this link of media use with development is supported by the fact that the High Social Use group was characterized by the highest average age and the highest percentage of girls of all groups. In contrast, the Low Use group had the lowest age.

Integrating the results in the current discussion on problematic media use, the classes Call Preference and High Social Use scored slightly above average on the MPPUS-10. This might be an indication that the need for social communication could drive problematic use to some extent. Still, none of the classes generally showed an extremely high score suggesting that high media use per se should not be a priori being considered problematic.

Regarding its clinical implications the results suggest that treatment for excessive media use in adolescents should build on the differences in psychosexual development, qualitative use preferences and its underlying motives. In this way this study supports the view that more tailored approaches are needed to address problematic media use in adolescents (Billieux, Schimmenti, et al., 2015; Schimmenti et al., 2015). 


\section{Strengths and Limitations}

A limitation of the study is the lack of longitudinal data so the direction of associations with the KIDSCREEN scales cannot be clarified. Thus the interpretation of any association has to be regarded with caution. The study had an unusual two stage sampling design which had high impact on the LCA. In both sampling stages there was one class with rather low and one with rather high media use predominant. The classes Low Use and Call Preference were highly prevalent in the sample $2012 / 2013$ (98.3\% and $73.6 \%$ of the class members, respectively) whereas two other classes, Medium Use and High Social Use consisted mainly from participants belonging to sample 2014/2015 (77.6\% and $87.6 \%$ ). Thus it seems likely that the differences in use patterns between Low Use/Medium Use and Call Preference/High Social Use depict the rapid development in media technologies within two years which was additionally paced by more affordable prices for flat rates included in smartphone subscriptions. Indeed, if we compare pairwise Medium Use with Low Use and separately High Social Use with Call Preference the classes more prevalent in sample 2014/2015 (Medium Use and High Social Use, respectively) showed the higher values on all variables related particularly to smartphone use (online on MP, text messages, social networks, music).

In this way, a multiple stage sampling design is an opportunity for assessing the rapid technology change and its accompanying effects.

\section{Conclusion}

Using latent class analysis is a fruitful approach to monitor specific patterns of media use on a population level. This approach could shed light onto the frequent but vague concerns of health effects due to media use in linking specific application use to specific outcomes. Nevertheless, appropriate research is challenging since mobile phones are an integral part in adolescents' life to gain independence. Additionally, communication technology and media use patterns are changing rapidly. Using latent class analyses to differentiate various usage types may be an appropriate way to better characterize and evaluate potential causal associations between media use and health related quality of life in adolescents. 


\section{References}

Abeele, M. V., \& Roe, K. (2013). Adolescents' school experience and the importance of having a "cool" mobile phone: Conformity, compensation and resistance? Poetics, 41(3), 265-293.

Andreassen, C. S., Torsheim, T., Brunborg, G. S., \& Pallesen, S. (2012). Development of a Facebook addiction scale. Psychological reports, 110(2), 501-517.

Banyai, F., Zsila, A., Kiraly, O., Maraz, A., Elekes, Z., Griffiths, M. D., . . Demetrovics, Z. (2017). Problematic Social Media Use: Results from a Large-Scale Nationally Representative Adolescent Sample. PloS one, 12(1), e0169839. doi:10.1371/journal.pone.0169839

Barrett, L. F., Lindquist, K. A., \& Gendron, M. (2007). Language as context for the perception of emotion. Trends in cognitive sciences, 11(8), 327-332.

Bian, M., \& Leung, L. (2015). Linking loneliness, shyness, smartphone addiction symptoms, and patterns of smartphone use to social capital. Social Science Computer Review, 33(1), 61-79.

Bianchi, A., \& Phillips, J. G. (2005). Psychological predictors of problem mobile phone use. CyberPsychology \& Behavior, 8(1), 39-51.

Billieux, J., Maurage, P., Lopez-Fernandez, O., Kuss, D. J., \& Griffiths, M. D. (2015). Can disordered mobile phone use be considered a behavioral addiction? An update on current evidence and a comprehensive model for future research. Current Addiction Reports, 2(2), 156-162.

Billieux, J., Schimmenti, A., Khazaal, Y., Maurage, P., \& Heeren, A. (2015). Are we overpathologizing everyday life? A tenable blueprint for behavioral addiction research. Journal of behavioral addictions, 4(3), 119-123.

Billieux, J., Van der Linden, M., \& Rochat, L. (2008). The role of impulsivity in actual and problematic use of the mobile phone. Applied Cognitive Psychology, 22(9), 11951210.

Bourdieu, P. (2011). The forms of capital.(1986). In I. Szeman \& T. Kaposy (Eds.), Cultural theory: An anthology (pp. 81-93): Wiley.

Choi, S.-W., Kim, D.-J., Choi, J.-S., Ahn, H., Choi, E.-J., Song, W.-Y., . . Youn, H. (2015). Comparison of risk and protective factors associated with smartphone addiction and Internet addiction. Journal of behavioral addictions, 4(4), 308-314.

Choo, H., Gentile, D., Sim, T., Li, D. D., Khoo, A., \& Liau, A. (2010). Pathological videogaming among Singaporean youth.

Correa, T., Hinsley, A. W., \& de Zúñiga, H. G. (2010). Who interacts on the Web?: The intersection of users' personality and social media use. Computers in Human Behavior, 26(2), 247-253. doi:http://dx.doi.org/10.1016/j.chb.2009.09.003

Demirci, K., Akgönül, M., \& Akpinar, A. (2015). Relationship of smartphone use severity with sleep quality, depression, and anxiety in university students. Journal of behavioral addictions, 4(2), 85-92.

Ding, W.-n., Sun, J.-h., Sun, Y.-w., Chen, X., Zhou, Y., Zhuang, Z.-g., . . Du, Y.-s. (2014). Trait impulsivity and impaired prefrontal impulse inhibition function in adolescents with internet gaming addiction revealed by a Go/No-Go fMRI study. Behavioral and Brain Functions, 10(1), 1.

Dolev-Cohen, M., \& Barak, A. (2013). Adolescents' use of Instant Messaging as a means of emotional relief. Computers in human behavior, 29(1), 58-63.

Ehrenberg, A., Juckes, S., White, K. M., \& Walsh, S. P. (2008). Personality and self-esteem as predictors of young people's technology use. CyberPsychology \& Behavior, 11(6), 739-741.

Ellison, N. B., Steinfield, C., \& Lampe, C. (2007). The benefits of Facebook "friends:" Social capital and college students' use of online social network sites. Journal of Computer-Mediated Communication, 12(4), 1143-1168.

Erikson, E. H. (1994). Identity: Youth and crisis: WW Norton \& Company. 
Feinstein, B. A., Hershenberg, R., Bhatia, V., Latack, J. A., Meuwly, N., \& Davila, J. (2013). Negative social comparison on Facebook and depressive symptoms: Rumination as a mechanism. Psychology of Popular Media Culture, 2(3), 161.

Foerster, M., Roser, K., Schoeni, A., \& Röösli, M. (2015). Problematic mobile phone use in adolescents: derivation of a short scale MPPUS-10. International journal of public health, 60(2), 277-286.

Foucault, M. (2002). The order of things: An archaeology of the human sciences: Psychology Press.

Hong, F.-Y., Huang, D.-H., Lin, H.-Y., \& Chiu, S.-L. (2014). Analysis of the psychological traits, Facebook usage, and Facebook addiction model of Taiwanese university students. Telematics and Informatics, 31(4), 597-606.

Kim, D., Nam, J. K., Oh, J., \& Kang, M. C. (2016). A latent profile analysis of the interplay between PC and smartphone in problematic internet use. Computers in human behavior, 56, 360-368.

Király, O., Griffiths, M. D., Urbán, R., Farkas, J., Kökönyei, G., Elekes, Z., . . Demetrovics, Z. (2014). Problematic internet use and problematic online gaming are not the same: findings from a large nationally representative adolescent sample. CyberPsychology, Behavior, and social networking, 17(12), 749-754.

Kisyovska, Y., Krönung, J., \& Eckhardt, A. (2015). Peer Influence, Family Dysfunction or Conditioning?-An Empirical Analysis of Facebook Addiction Predispositions. Paper presented at the Wirtschaftsinformatik.

Ko, C.-H., Liu, T.-L., Wang, P.-W., Chen, C.-S., Yen, C.-F., \& Yen, J.-Y. (2014). The exacerbation of depression, hostility, and social anxiety in the course of Internet addiction among adolescents: A prospective study. Comprehensive psychiatry, 55(6), 1377-1384.

Ko, C.-H., Yen, J.-Y., Yen, C.-F., Chen, C.-S., \& Chen, C.-C. (2012). The association between Internet addiction and psychiatric disorder: a review of the literature. European Psychiatry, 27(1), 1-8.

Kuss, D. J., \& Griffiths, M. D. (2012). Online gaming addiction in children and adolescents: A review of empirical research. Journal of behavioral addictions, 1(1), 3-22.

Lam, L. T. (2014). Internet gaming addiction, problematic use of the internet, and sleep problems: A systematic review. Current psychiatry reports, 16(4), 1-9.

Lee, H. C., Hong, M. H., Oh, C. K., Shim, S. H., Jun, Y. J., Lee, S. B., . . . Lim, M. H. (2015). Smart-Phone Addiction, Depression/Anxiety, and Self-Esteem with Attention-Deficit Hyperactivity Disorder in Korean Children. Journal of the Korean Academy of Child and Adolescent Psychiatry, 26(3), 159-164.

Lemola, S., Perkinson-Gloor, N., Brand, S., Dewald-Kaufmann, J. F., \& Grob, A. (2014). Adolescents' electronic media use at night, sleep disturbance, and depressive symptoms in the smartphone age. Journal of youth and adolescence, 44(2), 405-418.

Lo, S.-K., Wang, C.-C., \& Fang, W. (2005). Physical interpersonal relationships and social anxiety among online game players. CyberPsychology \& Behavior, 8(1), 15-20.

Mehroof, M., \& Griffiths, M. D. (2010). Online gaming addiction: the role of sensation seeking, self-control, neuroticism, aggression, state anxiety, and trait anxiety. CyberPsychology, Behavior, and social networking, 13(3), 313-316.

Mok, J.-Y., Choi, S.-W., Kim, D.-J., Choi, J.-S., Lee, J., Ahn, H., . . Song, W.-Y. (2014). Latent class analysis on internet and smartphone addiction in college students. Neuropsychiatric disease and treatment, 10, 817.

Müller, K., Beutel, M., Egloff, B., \& Wölfling, K. (2013). Investigating risk factors for internet gaming disorder: a comparison of patients with addictive gaming, pathological gamblers and healthy controls regarding the big five personality traits. European Addiction Research, 20(3), 129-136.

Nesi, J., \& Prinstein, M. J. (2015). Using social media for social comparison and feedbackseeking: gender and popularity moderate associations with depressive symptoms. Journal of abnormal child psychology, 43(8), 1427-1438. 
Nylund, K. L., Asparouhov, T., \& Muthén, B. O. (2007). Deciding on the number of classes in latent class analysis and growth mixture modeling: A Monte Carlo simulation study. Structural equation modeling, 14(4), 535-569.

Oh, H. J., Ozkaya, E., \& LaRose, R. (2014). How does online social networking enhance life satisfaction? The relationships among online supportive interaction, affect, perceived social support, sense of community, and life satisfaction. Computers in human behavior, 30, 69-78.

Ong, E. Y. L., Ang, R. P., Ho, J. C. M., Lim, J. C. Y., Goh, D. H., Lee, C. S., \& Chua, A. Y. K. (2011). Narcissism, extraversion and adolescents' self-presentation on Facebook. Personality and Individual Differences, 50(2), 180-185. doi:http://dx.doi.org/10.1016/i.paid.2010.09.022

Ostovar, S., Allahyar, N., Aminpoor, H., Moafian, F., Nor, M. B. M., \& Griffiths, M. D. (2016). Internet Addiction and its Psychosocial Risks (Depression, Anxiety, Stress and Loneliness) among Iranian Adolescents and Young Adults: A Structural Equation Model in a Cross-Sectional Study. International Journal of Mental Health and Addiction, 14(3), 257-267.

Pontes, H., \& Griffiths, M. (2014). Internet addiction disorder and internet gaming disorder are not the same. Journal of Addiction Research \& Therapy, 5(4).

Prensky, M. (2001). Digital natives, digital immigrants part 1. On the horizon, 9(5), 1-6.

Ravens-Sieberer, U., Gosch, A., Rajmil, L., Erhart, M., Bruil, J., Power, M., . . Kilroe, J. (2008). The KIDSCREEN-52 quality of life measure for children and adolescents: psychometric results from a cross-cultural survey in 13 European countries. Value Health, 11(4), 645-658. doi:10.1111/j.1524-4733.2007.00291.x

Rice, A. (2013). We are All Friends Nowadays: But What is the Outcome of Online Friendship for Young People in Terms of Individual Social Capital? Theory, and Practice: Perspectives from Ireland, 177-197

Roser, K., Schoeni, A., Foerster, M., \& Röösli, M. (2015). Problematic mobile phone use of Swiss adolescents: is it linked with mental health or behaviour? International Journal of Public Health, 1-9. doi:10.1007/s00038-015-0751-2

Roser, K., Schoeni, A., \& Röösli, M. (2016). Mobile phone use, behavioural problems and concentration capacity in adolescents: A prospective study. International Journal of Hygiene and Environmental Health, 219(8), 759-769. doi:http://dx.doi.org/10.1016/.i.jheh.2016.08.007

Schimmenti, A., Passanisi, A., Caretti, V., La Marca, L., Granieri, A., lacolino, C., . . Billieux, J. (2015). Traumatic experiences, alexithymia, and Internet addiction symptoms among late adolescents: A moderated mediation analysis. Addictive Behaviors.

Schou Andreassen, C., Billieux, J., Griffiths, M. D., Kuss, D. J., Demetrovics, Z., Mazzoni, E., \& Pallesen, S. (2016). The relationship between addictive use of social media and video games and symptoms of psychiatric disorders: A large-scale cross-sectional study. Psychology of Addictive Behaviors, 30(2), 252.

Selfhout, M. H., Branje, S. J., Delsing, M., ter Bogt, T. F., \& Meeus, W. H. (2009). Different types of Internet use, depression, and social anxiety: The role of perceived friendship quality. Journal of adolescence, 32(4), 819-833.

Shin, C. J., Yoon, C. S., \& Choi, H. (2015). A Study on Relation between Smartphone Addiction Factors and Gender: Focused on Adolescent. International Information Institute (Tokyo). Information, 18(6 (A)), 2233.

Steinfield, C., Ellison, N. B., \& Lampe, C. (2008). Social capital, self-esteem, and use of online social network sites: A longitudinal analysis. Journal of Applied Developmental Psychology, 29(6), 434-445.

Stetina, B. U., Kothgassner, O. D., Lehenbauer, M., \& Kryspin-Exner, I. (2011). Beyond the fascination of online-games: Probing addictive behavior and depression in the world of online-gaming. Computers in Human Behavior, 27(1), 473-479.

Suter, L., Waller, G., Genner, S., Oppliger, S., Willemse, I., Schwarz, B., \& Süss, D. (2015). MIKE-Medien, Interaktion, Kinder, Eltern. Retrieved from Zurich: 
Tandoc, E. C., Ferrucci, P., \& Duffy, M. (2015). Facebook use, envy, and depression among college students: Is facebooking depressing? Computers in human behavior, 43, 139146.

The KIDSCREEN Group Europe. (2006). The KIDSCREEN Questionnaires - Quality of life questionnaires for children and adolescents. Handbook. Lengerich: Pabst Science Publishers.

Thomée, S., Härenstam, A., \& Hagberg, M. (2012). Computer use and stress, sleep disturbances, and symptoms of depression among young adults-a prospective cohort study. BMC psychiatry, 12(1), 1.

Tofighi, D., \& Enders, C. K. (2008). Identifying the correct number of classes in growth mixture models. Advances in latent variable mixture models(Information Age Publishing, Inc), 317-341.

Trepte, S., \& Reinecke, L. (2013). The reciprocal effects of social network site use and the disposition for self-disclosure: A longitudinal study. Computers in Human Behavior, 29(3), 1102-1112.

van Deursen, A. J., Bolle, C. L., Hegner, S. M., \& Kommers, P. A. (2015). Modeling habitual and addictive smartphone behavior: The role of smartphone usage types, emotional intelligence, social stress, self-regulation, age, and gender. Computers in human behavior, 45, 411-420.

Viner, R. M., Ozer, E. M., Denny, S., Marmot, M., Resnick, M., Fatusi, A., \& Currie, C. (2012). Adolescence and the social determinants of health. The Lancet, 379(9826), 16411652.

Wager, T. D., Barrett, L. F., Bliss-Moreau, E., Lindquist, K., Duncan, S., Kober, H., . . Mize, J. (2008). The neuroimaging of emotion. The handbook of emotion, 3, 249-271.

Waller, G., Willemse, I., Genner, S., Suter, L., \& Süss, D. (2016). JAMES - Jugend, Aktivitäten, Medien - Erhebung Schweiz Retrieved from Zürich:

Wang, C.-W., Ho, R. T. H., Chan, C. L. W., \& Tse, S. (2015). Exploring personality characteristics of Chinese adolescents with internet-related addictive behaviors: Trait differences for gaming addiction and social networking addiction. Addictive Behaviors, 42, 32-35. doi:http://dx.doi.org/10.1016/j.addbeh.2014.10.039

Wölfling, K., Müller, K. W., \& Beutel, M. (2011). Reliability and validity of the Scale for the Assessment of Pathological Computer-Gaming (CSV-S). Psychotherapie, Psychosomatik, Medizinische Psychologie, 61(5), 216-224.

Yen, C.-F., Tang, T.-C., Yen, J.-Y., Lin, H.-C., Huang, C.-F., Liu, S.-C., \& Ko, C.-H. (2009). Symptoms of problematic cellular phone use, functional impairment and its association with depression among adolescents in Southern Taiwan. Journal of adolescence, 32(4), 863-873.

Young, K. S. (1998). Caught in the net: How to recognize the signs of internet addiction--and a winning strategy for recovery: John Wiley \& Sons.

Young, K. S., \& Rogers, R. C. (1998). The relationship between depression and Internet addiction. CyberPsychology \& Behavior, 1(1), 25-28.

Zhang, Y., Tang, L. S.-T., \& Leung, L. (2011). Gratifications, collective self-esteem, online emotional openness, and traitlike communication apprehension as predictors of Facebook uses. Cyberpsychology, Behavior, and Social Networking, 14(12), 733739. 